\title{
The Effect of Lacosamide Polytherapy on Seizure Prognosis in Focal Epilepsies
}

\section{(D) Mehmet Taylan PEKÖZ, ${ }^{1}$ (1) Hacer BOZDEMIR, ${ }^{1}$ (1) Ahmet Yusuf ERTURK, ${ }^{2}$ Ümit SATILMIŞ, ${ }^{3}$ (1) Kezban ASLAN KARA ${ }^{1}$}

1Department of Neurology, Çukurova University Faculty of Medicine, Adana, Turkey

${ }^{2}$ Department of Neurology, Muş State Hospital, Muş, Turkey

${ }^{3}$ Department of Neurology, Elbistan State Hospital, Kahramanmaraş, Turkey

\section{Abstract}

Objectives: What is expected from anti-epileptic treatment is low side effects and drug-drug interactions as well as high efficacy. In this study, the efficacy of lacosamide in polytherapy and its effect on prognosis were evaluated.

Methods: Seventy-seven patients with focal epilepsy who were followed up for at least 1 year and using lacosamide were included in the study. The antiepileptic drugs they use, the side effects of the drugs, neuroimaging and electrophysiological examinations were evaluated.

Results: A total of 77 patients, including 35 women (44.9\%) and 42 men (55.1\%), were included in the study. The mean age was $33.9 \pm 10.6$ (min: 19 max: 67). Average age of seizure onset was $12.6 \pm 10.7$, and none of the patients were using Lacosamide (LKS) as monotherapy. Although only 3 patients were receiving dual therapy, the remaining 74 patients were receiving 3 or more antiepileptic treatments. While 33 of the patients $(42.9 \%)$ had a decrease in the frequency of seizures after LKS treatment.

Conclusion: Although the percentage of efficacy was obtained as low according to literature information, lacosamide is effective in resistant focal epilepsies with an efficiency of $42.9 \%$. Especially in patients who use drugs other than antiepileptic drugs due to comorbid diseases, the absence of drug-drug interaction and the absence of serious side effects that require termination of treatment may be an indication that it can be used safely.

Keywords: Focal epilepsy; lacosamide; prognosis.

Cite this article as: Peköz MT, Bozdemir H, Erturk AY, Satılmış Ü, Aslan Kara K. The Effect of Lacosamide Polytherapy on Seizure Prognosis in Focal Epilepsies. Epilepsi 2021;27:150-154.

\section{Giriş}

Tüm yaş gruplarında ortaya çıkabilen epilepsiler, en sık görülen nörolojik hastalıklardan biridir. Tüm toplumun \%10'u yaşamları boyunca en az bir epileptik nöbet geçirebilmekte, bunların da 1/3'ünde nöbet rekürrensi olmakta ve sonuçta epilepsi tanısı almaktadır. Epilepsi hastalarının \%30-40'ında nöbetler konvansiyonel antiepileptik ilaç (AEI) politerapisine rağmen tam kontrol edilememektedir. Bu nedenle teda-

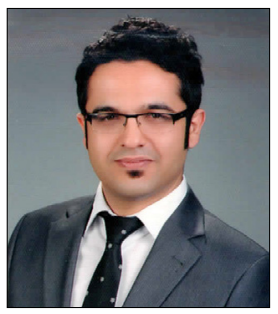

Corresponding autho Mehmet Taylan PEKÖZ, M.D. e-mail taylanpekoz@gmail.com

Received 17.03.2021

Accepted 18.05.2021

Online date 30.07.2021

Content of this journal is licensed under a Creative Commons Attribution-NonCommercial 4.0 International License.

(C) 2021 Turkish Epilepsy Society viye eklenen üçüncü jenerasyon AEl'ler ile nöbet sıklığında azalma ya da nöbet kontrolü sağlanabilmektedir. ${ }^{[1]}$

Üçüncü jenerasyon AEi'lerden biri olan Lakozamid (LKS), lineer farmakokinetik özelliğe sahip olup oral alım sonrası 1-2 saat içinde serumda pik düzeye, oral tedaviye başladıktan 3 gün sonra da etkili plazma konsantrasyonuna ulaşmaktadır. Eliminasyon yarı ömrü 13 saat olmakla birlikte proteinlere düşük oranda $(\leq \% 15)$ bağlanır. Hepatik izoenzim 2C19 (\%30) tarafından metabolize edilerek, \%0'dan fazlası böbreklerden değişmeden atılır. Illaç etkileşimi düşük olan LKS'nin hepatik CYP2C19 indükleyicileri ve inhibitörleri serum düzeyinde anlamlı değişikliğe neden olmamaktadır. Etkinliğini voltaj kapılı sodyum kanallarının yavaş inaktivasyonunu artırarak gösterir. ${ }^{[2-4]}$

Antikonvülsan etkisinin kısa sürede başlaması nedeni ile farkındalığın olduğu ya da olmadığı, motor ve non-motor fokal nöbetlerin tedavisinde ilave olarak 200-600 mg/gün 


\section{Fokal Epilepsilerde Lakozamid Politerapisinin Nöbet Prognozuna Etkisi}

\section{$\ddot{0} z$}

Amaç: Anti epileptik tedaviden beklenenler düşük yan etki ve ilaç-ilaç etkileşimi yanı sıra yüksek etkinliktir. Yan etki ve ilaç-ilaç etkileşiminin düşük olduğu bilinen lakozamidin politerapide etkinliği, prognoz üzerine etkisi değerlendirildi.

Gereç ve Yöntem: Çukurova Üniversitesi Tıp Fakültesi Epilepsi polikliniğinde ortalama 2 yıl (min: 1 maks: 3) süre ile takip edilen fokal epilepsi tanısı alan ve lakozamid kullanan 77 hasta çalışmaya dahil edilmiştir. Kullanmakta oldukları antiepileptik ilaçlar (AEi), yan etkileri, nörogörüntüleme ve elektrofizyolojik incelemeleri değerlendirilmiştir.

Bulgular: Otuz beş kadın (\%44.9) 42 erkek (\%55.1) olmak üzere toplam 77 hasta çalışmaya dahil edildi. Ortalama yaş $33.9 \pm 10.6$ (min: 19 maks: 67) idi. Ortalama nöbet başlama yaşı $12.6 \pm 10.7$ olup hastaların hiç biri Lakozamidi (LKS) monoterapi olarak kullanmamaktaydı. Sadece 3 hasta dual terapi almakta olmasına karşın geriye kalan 74 hasta 3'lü veya daha fazla antiepileptik tedavi almaktaydı. Hastaların 33'ünde (\%42.9) LKS tedavisi sonrası nöbet sıklığında azalma görülürken 44'ünde nöbet sıklığında değişiklik olmamıştır.

Sonuç: Her ne kadar literatür bilgilerine göre etkinlik yüzdesi düşük olarak elde edilmiş olsa da çalışmaya dahil edilen hastalar göz önüne alındığında, \%42.9'luk bir etkinlik ile lakozamidin dirençli fokal epilepsilerde etkin olduğunu göstermektedir. Özellikle komorbid hastalığa bağlı AEI dışında ilaç kullanan olgularda ilaç-ilaç etkileşiminin olmaması ve ciddi ya da tedaviyi sonlandırmayı gerektirecek bir yan etkinin gelişmemesi güvenle kullanılabileceği yönünde bir gösterge olabilir.

Anahtar sözcükler: Fokal epilepsi; lakozamid; prognoz.

dozunda uygulandığında, nöbet sıklığını anlamlı düzeyde azaltabilmektedir. ${ }^{[5,6]}$

LKS tedavisi sırasında diplopi, baş ağrısı, dizzines, ataksi, bulantı, özkıyım düşünceleri yanısıra, ilaç dozuna bağlı olarak PR intervalinde uzama, atrioventriküler blok, kardiyak iletim bozuklukları, atrial fibrilasyon hatta myokard iskemisi ve kalp yetmezliği gibi ağır kalp hastalıkları görülebilmektedir. Ayrıca eozinofili, hepatit, nefrit, lenfadenopati ve/veya miyokarditin eşlik ettiği multiorgan hipersensitivitesine de neden olabileceği dikkate alınmalıdır. ${ }^{[7]}$

Bu çalışmada, fokal epileptik nöbet tanılı 77 hastanın tedavisinde LKS ilavesinin nöbet frekansına ve prognoza etkisi değerlendirildi.

\section{Gereç ve Yöntem}

Bu geriye dönük çalışmada, Çukurova Üniversitesi Tıp Fakültesi Epilepsi polikliniğinde ortalama 2 yıl (min. 1 mak. 3) süre ile takip edilen hastalar arasından, jeneralize nöbet tanılı olgular dışlanarak, Uluslararası Epilepsi ile Savaş Komitesi'nin 2017 sınıflamasına göre ${ }^{[8]}$ fokal epilepsi tanılı LKS kullanan 77 hasta çalışmaya alındı. Çalışmaya dahil edilen hastaların daha önceden almakta oldukları monoterapi ya da politerapiyi etkili dozlarda almış olmaları dikkate alındı. Hastaların periyodik kontrolleri sırasında yapılan nörolojik muayenelerinde, tedaviye bağlı görülebilecek nörolojik toksik etkiler incelendi.

Hastaların önceden almakta oldukları tedavide sodyum (Na) kanallarına etkili AEI var ise, elektrokardiyografi (EKG) incelemesi yapıldı. Kalp hastalıkları ve bu nedenle kullandı- ğı tedavi protokolleri sorgulandı. ihtiyaç duyulan olgularda kardiyoloji konsültasyonu istendi.

Hastaların karaciğer-böbrek fonksiyonları, elektrolit değerleri, periferik kan örnekleri yanı sıra kullanılmakta olan AEi'ların yan etkilerine yönelik kalsiyum, sodyum, folik asit, vitamin $D$, vitamin $B 12$ serum düzeyleri kontrol edildi.

Tüm hastalarda rutin elektroensefalografi (EEG) incelemesi ( $m i n: 20 \mathrm{dk}$, maks: $30 \mathrm{dk}$ ) ile birlikte gerektiğinde ise en az 3 saat olmak üzere video EEG monitörizasyonu ve EEG kayıtlamaları sırasında EKG kayıtlaması da yapıldı. Tüm hastaların bilgisayarlı beyin tomografisi ve/veya manyetik rezonans görüntülemeleri (MRI) (1.5 ve 3 tesla) değerlendirildi.

Verilerin istatiksel analizinde IMB SPSS Statistics 21 sürümü kullanıımıştır. İi nitel değişkenin analizinde Pearson- $x^{2}$ testi, normal dağılıma sahip olmayan verilerde iki bağımsız grubun ölçüm değerleriyle karşılaştııılmasında "Mann-Whitney $\mathrm{U}^{\prime \prime}$ test (Z-tablo değeri) istatistikleri ve freakans tabloları kullanılmıştır.

\section{Bulgular}

Otuz beş kadın (\%44.9) 42 erkek (\%55.1) olmak üzere toplam 77 hasta çalışmaya dahil edildi. Ortalama yaş $33.9 \pm 10.6$ (min: 19 maks: 67) idi (Tablo 1). Ortalama nöbet başlama

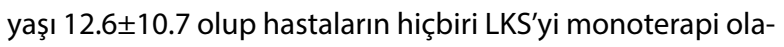
rak kullanmamaktaydı. Sadece 3 hasta dual terapi almakta olmasına karşın geriye kalan 74 hasta 3'lü veya daha fazla antiepileptik tedavi almaktaydı. Çoklu AEi tedavisine rağmen 32'si (\%41.6) ayda 1-3, 16'sı (\%20.8) haftada 1'den fazla ve $15^{\prime} \mathrm{i}(\% 19.5)$ haftada 1 nöbet geçirmektedir. Bu hastaların 
Tablo 1. Hastaların demografik özellikleri

\begin{tabular}{lc}
\hline & $\mathrm{n}$ \\
\hline Cinsiyet & \\
Kadın & 35 \\
Erkek & 42 \\
Yaş & \\
Ortalama & $33.9 \pm 10.6$ \\
En düşük & 19 \\
Lakozamid kullanım süresi ort. (ay) & $24.9 \pm 16.6$ \\
Tedavi (politerapi) & \\
İkili AEi & 3 \\
Üçlü AEi & 33 \\
Dörtlü AEi & 35 \\
Beşli AEi & 6 \\
Lakozamid sonrası nöbet sıklığı & \\
1. 1- $\uparrow /$ haftada & 15 \\
1 / haftada & 16 \\
1-3 / ayda & 32 \\
1-5 / 6 ayda & 8 \\
1 / yılda & 2 \\
1- $\downarrow$ /yılda & 28 \\
Etiyoloji & 47 \\
İiopatik & \\
Kriptojenik & \\
Semptomatik & \\
\hline
\end{tabular}

AEI: Anti epileptik ilaç; Ort.: Ortalama.

Tablo 2. Elektroensefalografi bulguları

\begin{tabular}{lcc}
\hline & $\mathrm{n}$ & $\%$ \\
\hline Normal & 3 & 3.9 \\
Fokal yavaş & & \\
$\quad$ Frontal & 4 & 18.2 \\
$\quad$ Temporal & 7 & \\
$\quad$ Fronto-temporal & 3 & \\
$\quad$ Toplam & 14 & \\
Fokal keskin & & \\
$\quad$ Frontal & 14 & 70.1 \\
$\quad$ Temporal & 26 & \\
$\quad$ Fronto-temporal & 10 & \\
$\quad$ Parietal-oksipital & 4 & \\
$\quad$ Toplam & 54 & \\
Jeneralize yavaş & 1 & 1.3 \\
Jeneralize keskin & 5 & 6.5 \\
\hline
\end{tabular}

EEG'leri incelendiğinde ise 54'ünde (\%70.1) fokal epileptik aktivite bozukluğu tespit edilmekle birlikte en sık görülen lokalizasyonun frontal ve temporal alanlar olduğu görüldü (Tablo 2).
Tablo 3. Manyetik rezonans görüntüleme bulguları

\begin{tabular}{lcc}
\hline & $\mathrm{n}$ & $\%$ \\
\hline Normal & 30 & 39 \\
Anormal & 47 & 61 \\
$\quad$ Serebral palsy sekeli & 14 & 18.2 \\
İskemi & 7 & 9.1 \\
Ensefalit sekeli & 5 & 6.4 \\
Mezial temporal skleroz & 4 & 5.2 \\
$\quad$ Sağ & 3 & \\
$\quad$ Sol & 1 & \\
Travma sekeli & 6 & 7.7 \\
İntrakranial kitle ve opere kitle & 5 & 6.4 \\
Diğer & 6 & 7.8 \\
\hline
\end{tabular}

Tablo 4. Lakozamid sonrası nöbet sıklığı

\begin{tabular}{lcc}
\hline & $\mathrm{n}$ & $\%$ \\
\hline Aynı & 44 & 57.1 \\
Azalmış & 33 & 42.9 \\
\hline
\end{tabular}

Tablo 5. Lakozamid sonrası ortaya çıkan yan etkiler

\begin{tabular}{lcc}
\hline & $\mathrm{n}$ & $\%$ \\
\hline $\begin{array}{l}\text { Yan etki } \\
\text { Yok }\end{array}$ & 65 & \\
$\quad$ Var & 12 & 15.6 \\
Baş ağrısı & 4 & 5.1 \\
Sersemlik & 2 & 2.5 \\
Uyku hali & 3 & 3.8 \\
Baş dönmesi+Baş ağrısı & 1 & 1.2 \\
Diplopi & 2 & 2.5 \\
\hline
\end{tabular}

Etiyolojiye yönelik yapılan MRI incelemelerinde 47 (\%61) hastada anormal bulgular (en sık serebral palsy $n=14 \% 29.7$ ) saptanırken 30'u (\%39) normal olarak değerlendirildi (Tablo 3). MRI'sında fokal bulgu tespit edilen hastalarda, normal olanlara göre prognozun daha kötü olduğu görüldü $(p=0.038)$. Ancak EEG bulgularının prognoza etkisi değerlendirilmek istendiğinde, çoklukla fokal epileptik aktivite tespit edilmiş olup, diğer EEG anormallikleri yeterli düzeyde olmadığından istatistiksel analizi yapılamadı.

LKS dozu 0-100 mg, 100-200 mg ve 200-400 mg aralıkları referans alınarak 3 ayrı grupta değerlendirilmiş ve nöbet sıklığı azalan hastaların 19'unun (\%57.5) 2. grupta olduğu dikkat çekmiştir. EEG ve MRI bulguları ile prognoz arasında istatistiksel olarak anlamlı ilişki saptanmadı. Etiyolojik açıdan değerlendirildiğinde en sık neden 47 hasta ile (\%61) 
semptomatik olup 14 hasta (\%29.7) ile serebral palsy ilk sIrada yer almaktaydı. On bir hastada (\%14.3) ailede epilepsi öyküsü olup hiçbiri birinci derece akraba değildi. Hastaların 33'ünde (\%42.9) LKS tedavisi sonrası nöbet sıklığında azalma görülürken 44'ünde nöbet sıklığında değişiklik olmamıştır (Tablo 4). On iki hastada (\%15.6) LKS ilavesine bağı yan etki görülmüş olmakla birlikte, hiçbir hastada yan etki nedeni ile AEI kesilmesine gerek görülmemiştir (Tablo 5). LKS sonrası prognozu aynı veya kötüleşmiş olan hasta grubuna bakıldığında kullandığı AEI sayısı ile korelasyon gösterdiği dikkati çekmiştir $(p=0.023)$.

\section{Tartışma}

LKS Avrupa, Amerika ve ülkemizde fokal nöbetlerde monoterapi veya ek tedavi açısından onam kazanmış olan bir moleküldür. Ülkemizde 2012 yılında ruhsat alan LKS 3. jenerasyon bir AEI olup yavaş sodyum kanalları üzerinden etkilidir. Proteinlere düşük oranda bağlanması, böbrekten metabolize olması, düşük ilaç-ilaç etkileşimi ve hızlı pik kan konsantrasyonuna ulaşması ile dikkatleri üzerine çekmiştir. ${ }^{[9,10]}$ Ancak reçete edilebilmesi için en az 6 ay ikili antiepileptik tedavi almış olma koşulu gerektiğinden genellikle dirençli epilepsilerde 3. veya 4. AEI olarak tercih edilebilmiştir. Benzer şekilde bizim çalışmamızda da LKS kullanan 77 hastanın sadece $3^{\prime}$ ünün $2^{\prime}$ Ii antiepileptik tedavi aldığı diğerlerinin ise 3'lü, 4'lü ve $5^{\prime}$ li tedavi almakta oldukları dikkat çekmektedir. Benzer şekilde Villanueva ve ark. ${ }^{[11]}$ LKS eklenen hastaların öncesinde veya halen kullanmakta olduğu AEI sayısı 1 ve 2 olanları "erken ek tedavi" olarak tanımlamış ve tedavi yanıııı bu grupta "geç ek tedavi" grubuna göre anlamlı yüksek olduğunu bildirmiştir.

Bizim hasta grubumuzda tedaviye yanıt olarak kabul ettiğimiz nöbet sıklığında azalma (\%42.9) literatüre göre daha düşük oranda bulunmuş olup hiçbir hastada nöbetsizlik görülmemiştir. ${ }^{[12]}$ Bunun nedenleri arasında hastaların önemli bir bölümünün semptomatik epilepsi tanılı olgular olması, çoklu antiepileptik tedavi kullanıyor olması, EEG'lerinde epileptik aktivite olması ve hatta komplianslarının iyi olmamasından kaynaklanan yeterli dozda ilaç kullanmamaları sayılabilir. LKS'nin önerilen ortalama dozu 200-400 mg/gün arası olup, daha yüksek dozlarda etkinlikte anlamlı bir değişiklik olmadığı gibi yan etkilerin daha sık görüldüğü bilinmektedir. ${ }^{[13]}$ Hastaların gerek sosyokültürel seviyelerinin düşüklüğünden, gerekse çoklu AEi kullanımının verdiği bıkkınlıktan ve hatta epileptik kişilik bozukluğu gibi psikiyatrik nedenlerden dolayı dosyalarında önerilen dozlarda kullanmadığı veya düzenli kontrollere gelmediği dikkati çekmiştir. Bu nedenle ilaç dozları 3 grupta (50-100 mg, 100-200 mg, 200$400 \mathrm{mg}$ ) değerlendirildiğinde 40 hastanın (\%51.9)'unun 2. grupta olduğu görülmektedir. Bu da nöbetsizlik veya nöbet sayısında azalmanın neden literatüre göre düşük olduğunun bir sebebi olabilir. Ancak 3. grupta yer alan yani etkin dozda ilaç kullanan 25 hasta kendi aralarında değerlendirildiğinde 7'sinde (\%28) nöbet sıklı̆ı̆ının azaldığı 18'inde ise aynı kaldığı dikkat çekmektedir. Bu da tek başına ilaç dozunun prognoz üzerinde etkili olmadığı yönünde yorumlanabilir. Tedaviye yanıtta etkisizliğin diğer bir nedeni de hastaların 47'si (\%61) gibi büyük bir çoğunluğunun semptomatik epilepsi tanılı olması ve 39'unun serebral MRI incelemesinin anormal olmasından kaynaklanabilir. Semptomatik epilepsi grubunda yer alan 47 hastadan 31'inde nöbet sıkığında değişiklik görülmemiş sadece 16 'sında nöbet sıklığı azalmıştır. Yine toplam sayıya baktığımızda nöbet sıklığında azalma olmayan 44 hastanın 31'i semptomatik grupta yer almaktadır.

Tedaviler incelendiğinde ise Koç ve ark.nın da belirttiği gibi kombinasyonlarda en çok tercih edilen ilacın karbamazepin (KBZ) olduğu ikinci sırada ise levetirasetamın tercih edildiği görülmektedir. ${ }^{[14]}$ Toplam 53 hastanın tedavi kombinasyonunda KBZ bulunmaktadır. KBZ ve LKS her ikiside farklı mekanizmalarla olsa da sodyum kanalları üzerinden etki etmektedir. Bu da akla acaba etkinlik veya yan etki açısından birlikte kullanıldığında ne gibi sonuçlar ortaya çıkıyor sorusunu getirmektedir. Arabi ve ark. ${ }^{[15]}$ sodyum kanal blokeri kombinasyonu yapılan hastalarda nöbet remisyonunun daha düşük olduğu yönünde görüş bildirmiştir. Bizim çalışmamızda da KBZ ile LKS'nin kombine edildiği hastalarda nöbet sıklığında azalma \%39.6 olmasına karşın, KBZ olmayan grupta \%50'dir. Her ne kadar prognoz üzerine tek etken anti epileptik ilaçlar olmasa da literatürde de belirtildiği gibi KBZ kullanmayan grupta prognozun daha iyi olması dikkat çekmektedir.

Yan etki açısından değerlendirdiğimizde ise LKS yan etki oranları, Koç ve ark. ${ }^{[14]}$ ile Eren ve ark.nın ${ }^{[16]}$ da belirttiği gibi literatüre göre daha düşük bulunmuştur. Bunun nedeni doz titrasyonunun daha yavaş yapılması veya ortalama dozun daha düşük olmasına bağlı olabilir. LKS ile KBZ birlikte kullanıldığında yan etki görülme sıklığı \%18.9 olarak saptanmıştır. KBZ olmayan grupta ise bu oran \%8.3'tür. Diplopi ve baş dönmesi yakınmaları olan hastaların tedavilerinde KBZ'nin olması da monoterapide dahi doz bağımlı olarak KBZ'nin diplopi, baş dönmesi, ataksi gibi yan etkilerinin olmasına bağlanabilir. ${ }^{[17]}$ En sık görülen yan etki baş ağrısı olup ortaya çıkan yan etkiler hastalar tarafından tolere edilebilmiş ve yan etki nedeni ile ilaç kesimi veya doz azaltımı olmamıştır. Çoklu antiepileptik ilaç kullanmaları nedeni ile daha kolay tolere edebilmiş ve şiddetli yan etki görülmemiş olabilir. Ancak beklenenin aksine LKS dozu ile yan etki görülme yüzdesi ters orantılı çıkmış yüksek dozlarda daha az yan etki görülmüştür. Bu da hasta sayısının azlığına ve doz dağılımında hasta sayısının birbirine yakın veya eşit olmamasına bağlanabilir. 
Sonuç olarak her ne kadar literatür bilgilerine göre etkinlik yüzdesi düşük olarak elde edilmiş olsa da çalışmaya dahil edilen hastalar göz önüne alındığında, \%42.9'luk bir etkinlik ile LKS'nin dirençli fokal epilepsilerde etkin olduğunu göstermektedir. Özellikle komorbid hastalığa bağlı AEl dışında ilaç kullanan olgularda ilaç-ilaç etkileşiminin olmaması ve ciddi ya da tedaviyi sonlandırmayı gerektirecek bir yan etkinin gelişmemesi güvenle kullanılabileceği yönünde bir gösterge olabilir. Tabi ki bunları daha net ve kesin söyleyebilmek için, bizim çalışmamızın da en büyük eksiği olan, daha fazla hasta sayısı ve daha uzun süre takip ile kayıtlamaların ve değerlendirmelerin yapılması olacaktır.

Informed Consent- Due to the retrospective design of the study, informed consent was not taken.

Ethics Committee Approval- This study was approved by the Çukurova University Faculty of Medicine Clinical Research Ethics Committee (Date: 22.01.2021; No: 107/20).

Peer-review- Externally peer-reviewed.

Authorship Contributions- Concept: M.T.P., H.B.; Design: M.T.P., H.B., K.A.K.; Supervision: H.B., K.A.K.; Data collection \&/or processing: Ü.S., A.Y.E.; Analysis and/or interpretation: A.Y.E. M.T.P.; Literature search: Ü.S.; Writing: M.T.P.; Critical review: M.T.P.

Conflict of interest- The authors declare that they have no conflict of interest.

Financial Disclosure: The authors declared that this study has received no financial support.

Hasta Onamı- Çalışmanın retrospektif tasarımından dolayı hasta onamı alınamamıştır.

Etik Komite Onayı- Bu çalışma Çukurova Üniversitesi Tıp Fakültesi Klinik Araştırmalar Etik Kurulu tarafından onaylandı (Tarih: 22.01.2021; No: 107/20)

Hakem Değerlendirmesi- Dış bağımsız.

Yazarlık Katkıları- Konsept: M.T.P., H.B.; Dizayn: M.T.P., H.B., K.A.K.; Kontrol: H.B., K.A.K.; Veri Toplama veya Işleme: Ü.S., A.Y.E.; Analiz ve Yorumlama: A.Y.E. M.T.P.; Literatür Arama: Ü.S.; Yazan: M.T.P.; Kritik Revizyon: M.T.P.

Çıkar Çatışması- Yoktur.

Finansal Destek- Yazarlar bu çalışma için finansal destek almadıklarını beyan etmişlerdir.

\section{Kaynaklar}

1. Kwan P, Brodie M. Early identification of refractory epilepsy. N Engl J Med 2000;(342):314-19. [CrossRef]

2. Steve $S$ Chung. Newly available treatments for epilepsy: review of clinical studies of lacosamide, ezogabine, perampanel and eslicarbazepine acetate. Clin Invest (Lond) 2014;4(9):839-46.
3. Thomas D, Scharfenecker U, Nickel B, Doty P, Cawello W, Horstmann R. Low potential for drug-drug interaction of lacosamide. Epilepsia 2006;47:200.

4. Ben-Menachem E. Lacosamide: an investigational drug for adjunctive treatment of partial-onset seizures. Drugs Today (Barc) 2008;44(1):35-40. [CrossRef]

5. Chung SS. New treatment option for partial-onset seizures: efficacy and safety of lacosamide. Ther Adv Neurol Disord 2010;3(2):77-83. [CrossRef]

6. Vossler DG, Knake S, O'Brien TJ, Watanabe M, Brock M, Steiniger-Brach B, et al; SP0982 co-investigators. Efficacy and safety of adjunctive lacosamide in the treatment of primary generalised tonic-clonic seizures: a double-blind, randomised, placebo-controlled trial. J Neurol Neurosurg Psychiatry 2020;91(10):1067-75. [CrossRef]

7. Li J, Sun M, Wang X. The adverse-effect profile of lacosamide. Expert Opin Drug Saf 2020;19(2):131-8. [CrossRef]

8. Scheffer IE, Berkovic S, Capovilla G, Connolly MB, French J, Guilhoto L, et al. ILAE classification of the epilepsies: Position paper of the ILAE Commission for Classification and Terminology. Epilepsia 2017;58(4):512-21. [CrossRef]

9. Chu-Shore CJ, Thiele EA. Dirençli fokal epilepside lakozamid ek tedavisi: 3. basamak merkez tecrübemiz. Epilepsi 2010;17(4):214-23.

10. Algın Di, Erdinç OO, Akdağ G. Fokal nöbetli hastalarda lakosamid ek tedavisi ile ilgili klinik deneyimler. epilepsi 2017;23(2):57-62.

11. Villanueva V, López FJ, Serratosa JM, González-Giraldez B, Campos $D$, Molins $A$, et al. Control of seizures in different stages of partial epilepsy: LACO-EXP, a Spanish retrospective study of lacosamide. Epilepsy Behav 2013;29(2):349-56. [CrossRef]

12. Neal A, D'Souza W, Hepworth G, Lawn N, Cook M, Nikpour A. Efficacy and tolerability of adjuvant lacosamide: The role of clinical characteristics and mechanisms of action of concomitant AEDs. Epilepsy Behav 2018;80:25-32. [CrossRef]

13. Gürses $A A$, Genç $E$, Genç BO. Lacosamide add-on treatment in refractory focal epilepsy: the experience of a single tertiary center. Epilepsia 2020;26(2):88-93. [CrossRef]

14. Koç G, Bek S, Karadaş Ö, Eroğlu E, Gökçil Z. Fokal başlangıçlı epilepside lakozamidin ek tedavideki yeri. Epilepsi 2017;23(3):1038.

15. Arabi M, Alsaadi T, Nasreddine W, Al-Hashel J, Dirani M, Beydoun A. Efficacy and tolerability of treatment with lacosamide: Postmarketing experience from the Middle East region. Epilepsy Behav 2018;84:118-21. [CrossRef]

16. Eren F, Dirican AC, Gül G, Tekin B, Atakli D, Baybaş S. Fokal başlangıçlı nöbetleri olan dirençli epilepsi hastalarında lakozamid ekleme tedavisinin kısa dönem sonuçları. Epilepsi 2021;27(1):47-51. [CrossRef]

17. Delcker A, Wilhelm H, Timmann D, Diener HC. Side effects from increased doses of carbamazepine on neuropsychological and posturographic parameters of humans. Eur Neuropsychopharmacol 1997;7(3):213-8. [CrossRef] 